\title{
IMAGINÁRIOS SOBRE APOSENTADORIA, TRABALHO, VELHICE: ESTUDO DE CASO COM PROFESSORES UNIVERSITÁRIOS ${ }^{1}$
}

\author{
Jacqueline de Oliveira Moreira*
}

\begin{abstract}
RESUMO. O presente texto apresenta os primeiros resultados da pesquisa "Aposentadoria e velhice bem-sucedida: estudo de caso com professores universitários". O objetivo principal da pesquisa é desvelar os conceitos e imaginários relativos à velhice, ao trabalho e à aposentadoria entre professores universitários com mais de 60 anos que continuam trabalhando. Neste artigo pretendemos refletir sobre os imaginários desses professores em relação à velhice e aos sentidos do trabalho, e sobre como estes dois elementos podem influenciar sua relação com a aposentadoria. Acreditamos que o imaginário negativo em relação à velhice leva os entrevistados a desvincular velhice $\mathrm{e}$ aposentadoria e que o trabalho, devido à sua valorização em nossa cultura, é tido como central na vida. Assim, manter o vínculo empregatício oferece diversos ganhos, como manter a valorizada condição de trabalhador e afastar os fantasmas de perdas e limitações da velhice; e, por fim, permite articular aposentadoria e continuidade do vínculo empregatício.
\end{abstract}

Palavras-chave: Velhice; aposentadoria; trabalho docente.

\section{WORK, RETIREMENT, OLD AGE: A CASE STUDY WITH UNIVERSITY PROFESSORS}

\begin{abstract}
This paper presents the first results of the research "Retirement and successful aging: a case study with university professors." The main goal of the research is to unveil concepts and the imaginary surrounding old age, work and retirement among professors over the age of 60 who still work. In this article, we reflect on the imaginary of teachers toward aging and the meanings of work, and how these two factors can influence their relationship with retirement. We believe that the imaginary negative toward aging leads these professors to separate old age and retirement, and that the work, due to its use in our culture, is considered the center of life. So, keep the employment situation offers many advantages: firstly, it maintains the highly valued worker status; secondly, it keeps away from the ghosts of losses and limitations associated with old age; lastly, it allows joint retirement and continued employment.
\end{abstract}

Key words: Old age; retirement; teaching work.

\section{TRABAJO, JUBILACIÓN Y VEJEZ: ESTUDIO DE CASO CON PROFESORES UNIVERSITÁRIOS}

\begin{abstract}
RESUMEN. Este texto presenta los primeros resultados de la pesquisa "Jubilación y vejez bien sucedida: estudio de caso con profesores universitarios". El objetivo principal de la pesquisa es desvelar los conceptos e imaginarios relativos a la vejez, al trabajo y a la jubilación entre profesores universitarios con más de 60 años que siguen trabajando. En este artículo nuestros objetos son el imaginario sobre la vejez y las ideas acerca del sentido del trabajo, y la comprensión de cómo ellos influyen en la visión sobre la posibilidad de jubilación. Creemos que el imaginario negativo en relación a la vejez lleva los entrevistados a desvincular vejez y jubilación, y que el trabajo, debido a su valorización en nuestra cultura, es tenido como central en sus vidas. Así, mantener el vínculo con el empleo ofrece diversas ventajas: primero, conserva la reconocida condición de trabajador; segundo, aleja los fantasmas de las pérdidas y limitaciones de la vejez; y, por fin, permite articular jubilación y continuidad del vínculo con el empleo.
\end{abstract}

Palabras-clave: Vejez; jubilación; trabajo docente.

Este texto apresenta os primeiros resultados da pesquisa "Aposentadoria e Velhice bem-sucedida: estudo de caso com professores universitários", financiada pelo Conselho Nacional de
Desenvolvimento Científico e Tecnológico (CNPq) no edital Universal 14/2010, pelo FIP, e aprovada pelo competente comité de ética $\mathrm{O}$ objetivo principal da pesquisa é desvelar os conceitos e imaginários em

Apoio: CNPq e Fundo de Incentivo à Pesquisa da PUC Minas (FIP-PUC MInas).

Doutora em Psicologia (Psicologia Clinica) pela PUC de São Paulo. Trabalha na PUC Minas, Brasil. 
relação à velhice, o trabalho e a aposentadoria entre professores universitários com mais de 60 anos que continuam trabalhando. Neste artigo nossos alvos são o imaginário sobre a velhice $\mathrm{e}$ as ideias sobre o sentido do trabalho, e como eles influenciam na visão sobre a possibilidade da aposentadoria. Entrevistamos seis professores em atividade: três mulheres, de 61, 63 e 88 anos de idade, e três homens, de 67, 73 e 80 anos de idade.

Sabemos que o problema do envelhecimento da população coloca perguntas sobre a relação com a aposentadoria. Este tema aparece em estudos recentes que enfatizam, sobretudo, as questões relacionadas à preparação para a aposentadoria (Rodrigues, Ayabe, Lunardelli \& Caneo, 2005; Muniz, 1997). Esses estudos concluem pela necessidade de se pensar em programas de preparação para esta fase da vida, pois o modo de produção capitalista elege o trabalho como ponto central da identidade. Segundo Rodrigues et al. (2005),

No modo de produção capitalista, que idolatra a produção e aliena o trabalhador do processo de produção, a aposentadoria é frequentemente vivenciada como a perda do próprio sentido da vida, uma espécie de morte social. Ao se valorizar apenas aqueles que produzem, deprecia-se o sujeito aposentado (Rodrigues et al., 2005, p. 54).

Somam-se ao fator acima mencionado os imaginários sobre a velhice, que podem influenciar diretamente a decisão de se aposentar. Algumas pesquisas tentam pensar na articulação entre esses fatores. No sentido de pesquisar a articulação entre o problema do envelhecimento da população e o tema do trabalho, podemos citar a pesquisa de Bulla e Kaefer (2003), que discutiu as dificuldades dos idosos para se manter no mercado de trabalho e a importância da preparação para a aposentadoria, e ainda a pesquisa de Giatti e Barreto (2003), que teve por objetivo a articulação entre a saúde e a possibilidade de manter a atividade profissional após os 60 anos. Segundo os autores, o objetivo do estudo foi "determinar os diferenciais de saúde dos idosos, segundo sua inserção no mercado de trabalho" (p. 759).

Nossa pesquisa compartilha da preocupação das pesquisas citadas, mas pretendemos articular três categorias: velhice, trabalho e aposentadoria. Não sabemos se a razão que mantém na ativa um professor já aposentado ou em condições de se aposentar é estritamente econômica ou se o envelhecimento e a aposentadoria são vividos como perdas que comprometem a identidade, ou ainda, se a manutenção da atividade profissional se vincula ao sentimento de vitalidade e satisfação com o trabalho. Assim, buscamos entrevistar seis professores universitários com mais de 60 anos para entender os motivos que os mantêm na atividade docente.

Podemos aplicar as ideias dos fatores push/pull, explicitados na próxima seção, para pensar essa dinâmica de não aposentadoria, ou de continuidade na atividade laboral, mas para entender os fatores que promovem a repulsa ou a atração de um professor universitário idoso quanto à manutenção do emprego, faz-se necessário definir o sentido do trabalho. Para realizar essa definição privilegiaremos duas referências clássicas, a saber, Freud e Frankl, sem esquecer as reflexões contemporâneas de França e Soares (2009), Morin, Tonelli e Pliopas (2007).

Parece importante ressaltar que utilizaremos neste texto a noção de aposentadoria vinculada à ideia de encerramento de contrato de trabalho, já que no Brasil é possível aposentar-se e fazer um novo contrato de trabalho. Assim, encontramos professores universitários que são aposentados e estabeleceram um novo contrato, como também professores com mais de 60 anos que não se aposentaram. Todos os sujeitos de nossa pesquisa são aposentados em outras instituições.

\section{POSIÇÃO QUANTO À APOSENTADORIA E AO TRABALHO À LUZ DA TEORIA DOS FATORES PUSH/PULL}

A teoria dos fatores push/pull ingressa no campo das ciências humanas através dos estudos sobre migração. Soares (2002) revela que muitas pesquisas que versam sobre o tema migração utilizam com instrumento de leitura a estrutura teórica denominada push/pull theory. O cidadão de um país busca outro país por um sentimento de repulsão (push) ou de atração (pull)? Os fatores de repulsão são muito frequentes em pessoas de baixo poder aquisitivo, que se sentem "expulsos" de seus países de origem devido aos baixos salários, por exemplo (Mata, Oliveira, Pin \& Resende, 2007). O contrário se aplica aos indivíduos de maior poder aquisitivo, que muitas vezes se sentem atraídos pela possibilidade de realizar suas potencialidades com maior desenvoltura e melhores condições em outro país (Mata et al., 2007).

Dessa forma, a teoria dos fatores push/pull é um recurso utilizado para pensar duas possibilidades no mesmo evento. Neste momento interessam-nos dois eventos diferentes no mesmo horizonte: a possibilidade legal da aposentadoria, a saber, a decisão de encerrar o vínculo empregatício, e a escolha de continuar na ativa profissional após os 60 
anos. Aplicando o instrumento push/pull no processo de decisão de finalização do vínculo empregatício entre profissionais com mais de 60 anos, podemos apresentar duas possibilidades: 1) o idoso pode se sentir expulso do trabalho por doença ou não reconhecimento, por exemplo; 2) o idoso pode se sentir atraído pela aposentadoria para usufruir o tempo livre. Pensando a possibilidade de continuar na ativa profissional, o idoso pode: 1) manter a atividade por sentir a aposentadoria como expressão da finitude ou por ter problemas financeiros, ou seja, sente repulsa à condição de estar sem vínculo empregatício; 2) sofrer a influência de fatores de atração como, por exemplo, a satisfação com o trabalho e o sentimento de vitalidade.

Parece-nos importante ressaltar que a valorização da ideia de terceira idade relaciona-se com a criação dos sistemas de aposentadoria e esta, por sua vez, vincula-se às movimentações do mercado de trabalho. A realidade da aposentadoria e o sistema previdenciário podem ser pensados como formas de solução para problemas decorrentes do processo de industrialização. A prática da aposentadoria veicula uma noção de envelhecimento associado a invalidez ou incapacidade; mas, segundo Debert (2007), essa imagem negativa possibilitou a aparição da ideia do idoso como um indivíduo de direitos. Podemos afirmar que a velhice, além de ser uma experiência individual, é fruto de um discurso que cria e recria conceitos compatíveis com as necessidades econômicas, políticas, científicas e históricas.

Segundo Shultz, Morton e Weckerle (1998), o grupo de baixa classe social é descrito como mais provável de se aposentar mais cedo por ser o trabalho insatisfatório e a aposentadoria ser considerada satisfatória; já os profissionais com maior qualificação tendem a se manter na atividade profissional (Shultz et al., 1998). França e Carneiro (2009) revelam que as decisões relativas à aposentadoria se relacionam com três níveis da vida: 1) o nível individual, familiar, emprego e carreira; 2) o nível organizacional; e 3 ) o nível ambiental. No nível individual temos os temas do emprego e da carreira; o organizacional diz do reconhecimento do sujeito na empresa; e o ambiental refere-se ao sentimento de realizar uma tarefa. Assim, o tema do trabalho parece decisivo. Neste sentido consideramos fundamental entender os significados do trabalho.

\section{TRABALHO E ALGUMAS DEFINIÇÕES}

Podemos afirmar que as imagens e ideias vinculadas ao conceito de trabalho sofreram várias transformações ao longo da história da civilização humana. Na verdade, a avaliação do sentido e do lugar do trabalho humano sai do extremo da desvalorização, da atividade considerada como inferior - portanto, obrigação dos subalternos -, no contexto da prémodernidade. Na modernidade, sobretudo após a Revolução Industrial, o trabalho alcança um lugar de maior valor, de algo que define a identidade e a existência de cada sujeito. No mundo contemporâneo o trabalho goza de um lugar privilegiado na vida das pessoas. Segundo França e Soares (2009), "para alguns trabalhadores, o trabalho está intimamente relacionado à sua identidade" (p. 741).

Sabemos, Assim, que o trabalho é apresentado pela sociedade contemporânea como uma atividade de alto valor; mas perguntamos: como a atividade laboral se inscreve no psiquismo humano? Qual seu sentido e significado? Segundo Tolfo e Piccinini (2007), os estudos sobre o sentido e o significado do trabalho ainda são escassos, e a maioria dos existentes tem como basea investigações desenvolvidas pelo Meaning of Work International Research Team (MOW, 1987) e, mais recentemente, por Morin (2001). Morin, Tonelli e Pliopas (2007), em estudo sobre o trabalho e seus sentidos, afirmam que os pesquisadores do grupo Meaning of Work International Research Team (MOW) são fortemente influenciados pela perspectiva da psicologia existencialista de Viktor Frankl, por isso optamos por enfatizar as concepções franklianas de trabalho.

$\mathrm{Na}$ concepção desse autor, o trabalho representa uma atividade humana que pode contribuir na busca de sentido para a existência humana. Frankl (1978/1989) revela a face saudável da relação com o trabalho, mas também a dimensão patológica. É a partir desses dois extremos que se desenvolve a leitura frankliana sobre a categoria de trabalho. O trabalho representa a possibilidade da concretização da escolha responsável que realiza a existência, ou seja, efetiva o caráter de algo único para cada existência humana. Segundo o mesmo autor, "a consciência da responsabilidade se desenvolve, sobretudo ao basearse na consciência de uma tarefa concreta e pessoal, isto é, de uma missão" (p. 159). A realização da missão pode ter sua consumação concreta no trabalho. O trabalho representa o campo em que o "caráter de algo único" da existência de um ser humano se relaciona com a comunidade; ou seja, o trabalho, além de possibilitar a realização do mundo interno, também cria condições de realização do mundo com outro. "O trabalho pode representar o campo em que o "caráter de algo único' do indivíduo se relaciona com a comunidade, recebendo assim o seu sentido e o seu 
valor" (p. 160). É importante ressaltar que o trabalho em si não representa uma forma de sentido, ou uma possibilidade de efetivar o caráter único e irrepetível da existência, para nós ele pode apenas ter essa representação; ou seja, é na relação que estabelecemos com a tarefa profissional que está contida a possibilidade de realização da existência. De acordo com Frankl (1978/1989),

A profissão concreta não traz consigo nenhuma sensação de plena satisfação, a culpa é do homem que a exerce, não da profissão. A profissão, em si, não é ainda suficiente para tornar o homem insubstituível; o que a profissão faz é simplesmente dar-lhe a oportunidade para vir a sê-lo (p. 160).

O exercício da profissão pode representar uma forma de sentido na vida e tornar única a vida do indivíduo, realizando sua singularidade na relação com os outros e consigo mesmo. Qualquer profissão oferece ao sujeito um "quadro de contínuas oportunidades para se realizar plenamente através do cunho pessoal que imprimir à respectiva obra profissional" (Frankl, 1978/1989, p. 160). O trabalho enquanto atividade profissional pode promover sentido não pela tarefa, pelo simples fazer, mas pelo modo como a tarefa é executada. Esse mesmo autor assim se refere ao trabalho:

(...) caráter insubstituível da vida humana, aquela impossibilidade de o homem ser representado por outrem no que só ele pode e deve fazer, o seu caráter de algo único: não do que ele faz, mas de quem o faz e do modo como faz (...) Assim, quando, por exemplo, uma enfermeira, para além das suas obrigações mais ou menos regulamentares, faz algo de pessoal; quando, por exemplo, acha uma palavra para dizer a um doente grave, - então, sim, conseguirá encontrar no trabalho profissional uma oportunidade para dar sentido à sua vida (p. 161).

Frankl (1978/1989) cunha a categoria de neurose de desemprego para abordar clinicamente aqueles que não conseguem concretizar o caráter único de sua existência em uma atividade profissional, seja pela falta de emprego, seja pela relação patológica com o emprego que têm. Assim, o significado existencial da profissão torna-se claramente visível quando desaparece totalmente o trabalho profissional e entra em cena a neurose de desemprego. "O desempregado experimenta a vivência da desocupação da sua época como uma desocupação interior” (p. 163). Não obstante, é essencial enfatizar que o desemprego não retira do sujeito o espaço de liberdade espiritual: "Na reação anímica perante o desemprego há bem pouco de fatal; que também aqui resta ainda muito espaço para a liberdade espiritual do homem" (p. 165). Frankl (1978/1989) não pretende negar o grave problema social do desemprego, ele apenas pensa ser preciso apresentar ao homem sua condição de liberdade dentro das diferentes determinações. Ante as determinações sociais de miséria e falta de emprego o homem pode continuar investindo em algo que concretize sua vida única e possibilite o encontro com o sentido autotranscendente.

É necessário ressaltar que tanto o desemprego como o trabalho profissional podem ser usados abusivamente como meios para um fim neurótico, e não como meios de realização de sentido. O trabalho é fundamental, mas a vida não se encerra nessa dimensão. "A capacidade de trabalho não é tudo, não constitui razão necessária nem suficiente para encher a vida de sentido" (Frankl, 1978/1989, p. 167).

É impressionante a atualidade da leitura de Frankl (1978/1989) sobre a categoria de trabalho. No mundo contemporâneo, do capitalismo sem limites, os sujeitos fogem da vida refugiando-se na vida profissional. O homem que nada mais é do que o homem do trabalho perde a possibilidade de realizar sua existência: ele apenas executa tarefas mecanicamente em busca de dinheiro para o consumo desenfreado. Esse mesmo homem apresenta, segundo Frankl (1978/1989), uma neurose dominical: "No domingo, em se detendo o ritmo de trabalho dos dias úteis da semana, põe-se a nu a pobreza de sentido característico da vida cotidiana das grandes cidades" (p. 168).

O domingo revela-se insuportável, pois apresenta a face nua e crua de uma vida sem sentido transcendente. As leituras franklianas sobre a neurose do desemprego podem nos auxiliar na investigação sobre a relação dos sujeitos com a aposentadoria; pois, como afirma Chauí (2000), o capitalismo faz crer que todos têm o dever moral e social de possuir um trabalho, criando para a condição de não trabalho (como o desemprego ou a aposentadoria) atributos como culpa e vergonha.

A ideia de pensar o trabalho como inscrição psíquica de sentido é interessante, mas não podemos esquecer que o trabalho é essencial para garantir a sobrevivência e que o elemento salário é decisivo. Pensar o trabalho como garantia de sobrevivência não é reduzir a atividade profissional ao campo da necessidade. Neste sentido, a teoria freudiana pode nos oferecer uma compreensão sobre o lugar do 
trabalho no campo da dialética "necessidade e desejo", pensando necessidade como o espaço das exigências básicas de sobrevivência e desejo como uma inscrição humana que revela a face da busca de reconhecimento pelo outro.

Freud (1930/1997) busca nos primórdios da civilização elementos para compreender a exigência de trabalho. $O$ autor refere que a condição de desamparo ante as situações aversivas da natureza coloca a urgência do agrupamento e a necessidade do trabalho. O trabalho aparece como uma defesa contra as imprevisibilidades ocasionadas pela natureza. $\mathrm{O}$ homem se percebe numa condição de insuficiência diante do limite de suas forças para extinguir ou estabelecer um maior controle sobre as adversidades da natureza. Assim ele percebe a necessidade do laço social com o outro:

Depois que o homem primevo descobriu que estava literalmente em suas mãos melhorar a sua sorte na Terra através do trabalho, não lhe pode ter sido indiferente que outro homem trabalhasse com ele ou contra ele. Esse outro homem adquiriu para ele o valor de um companheiro de trabalho, com quem era útil conviver. Em época ainda anterior, em sua pré-história simiesca, o homem adotara o hábito de formar famílias, e provavelmente os membros de sua família foram os seus primeiros auxiliares (Freud, 1930/1997, p. 119).

Eis aí a gênese também da sociabilidade segundo a ótica freudiana. Assim, o trabalho é apontado por Freud como um fator de motivação para reunião social entre os homens. Para ele o trabalho comporta essa função social conjuntamente com os impulsos sexuais. Assim a vida comunitária dos seres humanos teve um fundamento duplo: a compulsão para o trabalho, criada pela necessidade externa, e o poder do amor, que fez o homem relutar em privar-se de seu objeto sexual - a mulher - e a mulher, em privar-se daquela parte de si própria que dela fora separada - seu filho. Eros e Ananke (Amor e Necessidade) tornaram-se os pais também da civilização humana. $\mathrm{O}$ primeiro resultado da civilização foi que mesmo um número bastante grande de pessoas podia agora viver reunido numa comunidade. Ora, como esses dois grandes poderes cooperaram para isso, poder-se-ia esperar que o desenvolvimento ulterior da civilização progredisse sem percalços no sentido de um controle ainda melhor sobre o mundo externo, e no de uma ampliação do número de pessoas incluídas na comunidade (Freud 1930/1997). Formando famílias, o homem obteve a garantia de auxiliares para o desempenho de demandas derivadas de suas atividades.

Desse modo, podemos perceber que, na perspectiva freudiana, o trabalho é um fator de civilização e uma expressão de sublimação, mas somente a minoria está bem disposta a realizar o trabalho sublimatório pela construção da civilização segundo Freud (1930/1997), por causa da oposição entre trabalho e felicidade. A relação do trabalho com a felicidade é pouco explicitada, mas podemos apontar algumas pistas. $\mathrm{O}$ trabalho definido pela exigência das tarefas carece de maior espontaneidade. Na concepção freudiana o reconhecimento das potencialidades e a possibilidade do desenvolvimento das habilidades apontam na direção da felicidade na atividade laboral. A ausência de clareza no emprego das capacidades, inclinações e dotes de um homem constantemente o levaria à produção de insatisfação quanto à atividade profissional por ele desempenhada. Dessa forma, Freud parece convidar a um autoconhecimento dos atributos e disposições particulares de um indivíduo.

Entendemos que o trabalho, na perspectiva freudiana, é primeiramente, uma atividade que visa diminuir o desamparo humano, mas que, consequentemente, possibilita a vinculação com o outro, a convivência, portanto, a inserção social, e nessa perspectiva, o trabalho pode oferecer uma via de reconhecimento. Segundo Morin et al. (2007), os elementos que contribuem para o trabalho ter sentido são: “(...) ter variedade e ser desafiador; possibilitar aprendizagem contínua; permitir autonomia e decisão; possibilitar reconhecimento e apoio; trazer uma contribuição social e permitir um futuro desejável" (p. 48).

Concordamos com Morin et al. (2007) quando afirmam que o trabalho deve relacionar três dimensões: a dimensão, individual (satisfação pessoal, independência e sobrevivência, crescimento e aprendizagem, identidade), a dimensão organizacional (utilidade, relacionamento, inserção social) e a dimensão social (contribuição social).

Assim, na tentativa de compreender o sentido do trabalho e da aposentadoria para os professores universitários, realizamos as entrevistas mencionadas anteriormente. Sabemos, a partir dos estudos de França e Vaughan (2008) com executivos, que a aposentadoria tem dimensões positivas, tais como: liberdade do trabalho, mais tempo para os relacionamentos, novo começo e mais tempo para atividades culturais e de lazer e para os investimentos. Sabemos também que há dimensões negativas, como os aspectos emocionais do trabalho, os aspectos tangíveis do trabalho os relacionamentos do trabalho e 
os salários; porém não podemos negar que os imaginários sobre a velhice influenciam diretamente a posição sobre a aposentadoria.

Assim, com o objetivo de desvelar conteúdos imaginários sobre velhice e aposentadoria entre professores universitários com mais de 60 anos, optamos pela pesquisa qualitativa, mais especificamente por um estudo de caso cuja coleta de dados foi feita por meio de entrevistas semiestruturadas. Segundo González Rey (2002), uma epistemoloogia qualitativa deve se sustentar por formas distintas de produção de conhecimento, que possibilitem tanto a criação teórica acerca da realidade - que é em si multideterminada, dinâmica e histórica quanto a cuidadosa e ampla elaboração das ideias e fatos procedentes do empírico. Cabe ressaltar que a abordagem qualitativa do estudo da subjetividade procura realizar a elucidação de processos complexos e buscar os sentidos subjetivos e processos de significação a partir dos quais se dá a construção do conhecimento. Dentro da pesquisa qualitativa elegemos o estudo de caso que, segundo Chizzotti (2003),

é uma caracterização abrangente para designar uma diversidade de pesquisas que coletam e registram dados de um caso particular ou de vários casos a fim de organizar um relatório ordenado e crítico de uma experiência, ou avaliá-lo analiticamente, objetivando tomar decisões a seu respeito ou propor uma ação transformadora (p. 102).

Para Laville e Dionne (1999), o estudo de caso pode ser o de uma pessoa, mas também de um grupo, de um meio, podendo até mesmo fazer referência a uma mudança política ou um acontecimento especial. Considerando essas definições de estudo de caso, optamos por essa metodologia de pesquisa para estudar um grupo de professores na sua relação com um acontecimento específico: a aposentadoria. A entrevista semiestruturada foi o instrumento de coleta de dados. $\mathrm{Na}$ análise desse instrumento explicitamos palavras que definiam a relação do entrevistado com os temas ordenadores da pesquisa - velhice, aposentadoria e trabalho -, ressaltando tanto os pontos positivos quanto os negativos ligados a cada categoria. Foram entrevistados seis professores universitários que, embora já aposentados, mantêm-se em atividade. Para isto foram seguidos os seguintes eixos norteadores:

1. identificação (sexo, idade, situação conjugal, situação profissional, situação médica);
2. percepções do envelhecimento (percepções do próprio envelhecimento e como você definem o fenômeno);

3. definições de trabalho (definição pessoal de trabalho: (Qual é a sua definição de trabalho? Qual o lugar do trabalho em sua vida? Sente satisfação, motivação e reconhecimento de seu trabalho? Como você se sente no seu espaço de trabalho?);

4. imaginários sobre a aposentadoria (fantasias pessoais: "Na sua opinião, o que significa se aposentar? Quais são os motivos que o/a levaram a continuar trabalhando?; posições sociais: "Como você acha que a sociedade considera a situação de não trabalhar? Você acha que a aposentadoria afeta a posição social do idoso?"; fatores push/pull: "Você se sente atraído para continuar no trabalho ou tem uma visão negativa da aposentadoria?").

Ao final da discussão sobre os eixos listados, solicitamos ao entrevistado que explicitasse sua posição em relação a cada um deles: o mais positivo ou o mais negativo.

\section{RESULTADOS E DISCUSSÃO DO ESTUDO DE CASO}

As concepções de P1 (mulher, 61) em relação à velhice, trabalho e aposentadoria não são totalmente negativas. P1 diz que existe uma vantagem no envelhecimento, que é a segurança: "Você se sente mais segura, você tem.. é... mais experiência". Ela inicia sua resposta sobre aposentadoria afirmando que não tem uma visão negativa, mas essa oscilação parece-nos fruto de um esforço de pensamento, e não de um sentimento imediato, já que nas suas primeiras definições de velhice a entrevistada acentua a dimensão das perdas e da morte. "Eu, quando penso em envelhecimento, eu penso nas perdas que a gente vai tendo. Primeiramente o que vem à mente são essas perdas, essas perdas físicas, né, de você tá num envelhecimento da pele, envelhecimento do corpo" (P1).

Em relação à categoria de trabalho, $\mathrm{P} 1$ destaca os elementos da necessidade do trabalho e da sua importância em uma sociedade capitalista, mas enfatiza sua relevância para a troca e o convívio social: "Ele tem também o papel de manter o convívio social, né, de manter a gente ligada na realidade, no cotidiano" (P1). Assim, o significado do trabalho para P1 aproxima-se da ideia freudiana do trabalho como forma de vínculo social. É importante ressaltar que, 
para $\mathrm{P} 1$, o trabalho oferece uma forma de identidade: "Eu nunca assumi o lugar somente de mãe, ou somente de dona de casa, os papéis femininos tradicionais. Eu sempre fui uma mulher trabalhadora, então ele [o trabalho] sempre teve um papel fundamental" (P1).

A vinculação do envelhecimento com a morte associada à ideia do trabalho como formador de identidade coloca a aposentadoria como encerramento dos vínculos empregatícios, como uma morte. Parar de trabalhar significa perder uma identidade. E mais, a visão do trabalho é positiva e a aposentadoria, ou não trabalho, representa uma passagem para a solidão e o tédio. É interessante ressaltar que P1 inicia sua resposta com uma negativa:

Eu não tenho uma visão negativa sobre a aposentadoria, pode ser um tempo bom, mas, por outro lado, tenho... como eu nunca vivi um tempo assim, eu tenho medo também que esse tempo seja muito chato, né? Que ele, é, possa significar, por exemplo, é menos convivência social.

Freud (1925/1997) afirma que a negativa pode constituir um modo de tomar conhecimento do que está recalcado. O autor revela que "o conteúdo de uma imagem ou ideia reprimida pode abrir caminho até a consciência, com a condição de que seja negada" ( $p$. 295). Quando afirma "eu não tenho uma visão negativa sobre a aposentadoria" P1 revela um conteúdo que não pode habitar a consciência de uma visão ruim da aposentadoria. Podemos concluir a entrevistada apresenta uma atração pela condição de trabalhadora e um sentimento de repulsa em relação à condição de não trabalho, na medida em que a associa à solidão.

P2 (homem, 73 anos) acredita que a velhice está associada à aposentadoria, mas pensa as duas categorias associadas à doença e à incapacidade de trabalhar. Este entrevistado não se sente velho nem aposentado, pois sua forte e saudável vinculação ao trabalho representa o élan vital que o conecta à vida. A velhice é definida como a incapacidade de trabalhar. "Velhice é quando você não pode mais trabalhar, aí eu estou velho. Eu, por exemplo, pra mim, no dia que eu não puder mais trabalhar, eu vou ficar muito chateado e aí eu vou me sentir velho" (P2). O trabalho aparece, para P2, como uma fonte para sustentar a autoestima, e como uma terapia. P2 apresenta-nos uma concepção de desenvolvimento que se aproxima da tese do lifespan, ou seja, do desenvolvimento ao longo da vida. Para esse professor, continuar trabalhando significa "continuar progredindo, aprendendo".
Assim, para P2, a velhice ativa está estreitamente vinculada à possibilidade de manter a atividade profissional. O professor vê a oportunidade de dar aulas como um presente divino, porque ela o convoca para a vida.

Eu falo pra você, esse ato de passar a
experiência pro outro é um ato de amor, é
um ato que não deixa envelhecer. (...) Eu
falo que Deus me deu a PUC porque Deus
me deu na PUC a oportunidade de cada ano
eu pegar alunos mais novos e eu vou
convivendo com a juventude (P2).

O significado do trabalho para P2 aproxima-se da definição frankliana, que revela um sentido na realização da tarefa; e o envelhecimento é associado à doença, à falta de objetivos, e a aposentadoria é a expressão desse fim.

Quando a pessoa deixa de ter esse sonho, essa percepção de que ela vai fazer pra frente, é o fator que identifica a pessoa de terceira idade, normalmente a pessoa de terceira idade, no meu entender ela não vê mais futuro, ela quer parar, quer ficar em casa $(\mathrm{P} 2)$.

P2 apresenta uma forte atração pela situação de continuar trabalhando, e a aposentadoria seria a impossibilidade de intervir no mundo.

Eu vou ficar aposentado quando eu tiver sem saúde, pra mim a aposentadoria, tirando o recebimento do dinheiro, que não é ruim, mas do ponto de vista de definição de aposentadoria, seria a definição da pessoa parar de agir, não é de trabalhar, não, é parar de agir $(\mathrm{P} 2)$.

A terceira entrevistada, de 88 anos (P3), revela que sua visão da velhice é positiva, considerando o seu próprio processo de envelhecimento, ou seja, envelhecer trabalhando, porque. para esta professora o trabalho significa liberdade do pai, do marido, e liberdade intelectual. " $\grave{A}$ medida que eu envelheço, como eu estou envelhecendo, trabalhando, com essa idade, tendo o respeito de toda a comunidade científica, eu acho que aí é um ponto muito positivo, sabe" (P3). Ela não explicita a vinculação entre a velhice bem-sucedida e a manutenção da atividade profissional, mas afirma com entusiasmo seu sucesso junto à comunidade científica.

$\mathrm{O}$ quarto entrevistado ( $\mathrm{P} 4)$ define a velhice como a incapacidade de trabalhar, sendo a atividade profissional a essência da vida: "Qual o lugar do 
trabalho em sua vida? P4: "Total. Minha vida, ela depende estritamente do trabalho, né? Trabalho pra mim é uma questão prioritária na vida".

A aposentadoria, definida como encerramento das atividades profissionais, aparece associada à velhice e à incapacidade de trabalhar, portanto vincula-se a sentimentos negativos. As duas noções revelam a face da morte, da inutilidade, da incapacidade. O trabalho possui uma força identitária que sobrevive ao envelhecimento.

È importante ressaltar que os entrevistados se sentem atraídos pela atividade profissional e que, para eles, continuar trabalhando aponta para o pulsar da vida. A força de repulsa à situação de não trabalho é menor que a força de atração da manutenção do vínculo empregatício. As definições de trabalho de P2, P3, P4, P5 e P6 se aproximam mais da definição frankliana do trabalho como fonte de sentido.

$\mathrm{O}$ quinto entrevistado define a velhice prioritariamente como perda: "O envelhecimento eu defino como a perda, isso em uma situação normal" (P5 - homem, 67 anos). Este professor apresenta uma vinculação com o trabalho diferente dos demais. Para ele o trabalho está em segundo lugar. Como consequência dessa sua relação com o trabalho, P5 parece ser o entrevistado que mais considera a possibilidade da aposentadoria como encerramento das atividades profissionais.

\begin{abstract}
Aposentar é aquela hora que você se sente bem... você não vai sentir falta do seu trabalho, que você tem uma outra atividade prazerosa, e que você já tenha amealhado recursos pra levar uma vida com o mesmo nível de conforto que você sempre levou (P5).
\end{abstract}

P5 continua a atividade profissional pelo prazer e reconhecimento que ela oferece, mas acredita ser fundamental para a manutenção da saúde psíquica manter atividades após a aposentadoria. Veja a resposta de PS5à pergunta "Quais são os motivos que o levaram a continuar trabalhando?": Em relação ao ensino, por gostar". Quando interrogado se a manutenção da atividade profissional possibilita a vivência de uma velhice saudável ele responde: " $E u$ acho importante qualquer tipo de atividade, mesmo que não remunerada, para você se manter ativo". Assim, a relação de P5 com o trabalho parece não reproduzir o modelo social vigente do trabalho como centro da vida, por isso o professor pensa a possibilidade da aposentadoria e as ações que precisam ser implementadas.

\begin{abstract}
Eu, que gosto de informática, eu já tenho, eu já sei o que eu vou fazer quando eu não estiver fazendo nada, eu gosto muito de informática, me mantenho atualizado, entendo, já estudei informática, inclusive fiz um curso longo aqui na própria PUC. Alguns anos atrás a PUC ofereceu um curso mais de um ano, eu fiz esse curso, me aperfeiçoei, então, remunerado ou não, eu vou me dar bem na informática (P5).
\end{abstract}

$\mathrm{Na}$ concepção de P6 (mulher, 63 anos), o envelhecimento é natural, mas o problema se coloca quando as limitações aumentam: "Como eu te disse, é um processo natural. Vai chegar uma hora que eu não vou conseguir atender minhas expectativas, aí eu acho que eu vou estar realmente na velhice". Essa entrevistada usa uma metáfora da física para definir trabalho, mas deixa claro o lugar importante que o trabalho ocupa em sua vida. Ela estabelece uma interessante separação entre aposentadoria e velhice, que esclarece o imaginário sobre a velhice como fim e do trabalho como sentido de vida: "Aposentadoria eu considero você continuar ganhando sem ter as obrigações. Velhice é quem não consegue realizar aquilo que quer. Então, pelos meus conceitos não tem relação nenhuma [entre velhice e aposentadoria]" (P6). Para ela, a aposentadoria seria negativa se estivesse vinculada ao encerramento das atividades profissionais:

\footnotetext{
Se você considera aposentado como o parar de trabalhar, eu tenho uma visão negativa, sim. Como eu te falei, cada pessoa é de um jeito, como eu trabalhei a minha vida inteira eu não tenho vontade nenhuma de parar. Se eu penso em parar de trabalhar eu tenho uma visão muito negativa, eu não quero, nem passa pela cabeça $(\mathrm{P} 6)$.
}

Parece-nos fundamental enfatizar que todos os entrevistados afirmam que a posição social do idoso é delicada. P6, por exemplo, afirma: “(...) a nossa sociedade supervaloriza a juventude e despreza a velhice (...).

Acreditamos que o imaginário negativo em relação à velhice produz nos entrevistados o movimento de desvinculação entre velhice e aposentadoria, e que, devido à sua valorização em nossa cultura, o trabalho é tido como algo central na vida. Assim, manter o vínculo empregatício oferece diversos ganhos: mantém uma situação de valor, a condição de trabalhador, afasta os fantasmas de perdas e limitações da velhice e permite articular 
aposentadoria com a continuidade do vínculo empregatício.

\section{CONSIDERAÇÕES FINAIS}

Os professores entrevistados operam uma dissociação entre aposentadoria, velhice e trabalho. A aposentadoria não deve ser entendida como o fim das atividades profissionais: a velhice é caracterizada quando "não consegue realizar aquilo que quer" (P6). Somente o professor de 67 anos pensa na aposentadoria e na manutenção da saúde por meio do engajamento em alguma atividade: "Eu acho importante qualquer tipo de atividade, mesmo que não remunerada, para você se manter ativo" (P5).

Podemos levantar a hipótese de que encerrar as atividades profissionais coloca um dilema: descanso ou trabalho. Como afirma Chauí (2004), a sociedade capitalista recrimina a situação de não trabalho, e assim não há espaço para o descanso.

A posição sobre aposentadoria como encerramento de vínculos empregatícios está estreitamente vinculada aos imaginários sobre a velhice e aos significados do trabalho. Todos os professores entrevistadas sentem a velhice como perda. $\mathrm{O}$ forte imaginário negativo em relação à velhice, associado à vinculação do trabalho como o mais importante elemento definidor da identidade, coloca a aposentadoria, se entendida como não trabalho, como expressão da incapacidade.

A relação destes seis professores com o trabalho preenche as três dimensões anunciadas por Morin et al. (2007), pois todos revelam satisfação pessoal, crescimento e aprendizagem; sentem-se inseridos e contribuindo para a sociedade. É interessante enfatizar que, para as mulheres, o trabalho apresenta uma possibilidade de independência. Assim, a aposentadoria aparece como um benefício possível, desvinculado da velhice. Além disso, a manutenção do vínculo empregatício, entre os professores universitários entrevistados após a aposentadoria, não se deve a problemas econômicos. $\mathrm{O}$ encerramento do contrato indicaria uma situação de incapacidade, morte e perda de identidade, mas, por outro lado, para estes profissionais que se sentem reconhecidos em suas atividades, trabalhar possibilita uma vivência de saúde. Desta forma, os professores se sentem atraídos (fator pull) pela situação de contrato de trabalho. Para eles, a aposentadoria é atraente se pensada como um benefício, e não como o encerramento das atividades profissionais.

\section{REFERÊNCIAS}

Bulla, L. C., \& Kaefer, C. O. (2003). Trabalho e aposentadoria: as repercussões sociais na vida do idoso aposentado. Revista Virtual Textos \& Contextos, 2(2) Recuperado em 15 de junho, 2011, de http://revistaseletronicas.pucrs.br/ojs/index.php/fass/article/view/ 957

Chauí, M. (2000). Convite à filosofia. São Paulo: Ática.

Chauí, M. (2004). O retorno do teológico-político. Recuperado em 2 de julho, 2011, de http://www.ces.uc.pt/bss/documentos/o_retorno_do_teologico.pdf

Chizzotti, A. (2003). Pesquisa em ciências humanas e sociais. 6a ed. São Paulo: Cortez.

Debert, G. G. (2007). A invenção da terceira idade e a rearticulação de formas de consumo e demandas políticas. Revista Brasileira de Ciências Sociais (RBCS/ANPOCS), 12(34), 39-56. Recuperado em 21 de junho, 2011, de http://www.anpocs.org.br/portal/publicacoes/rbcs_00_34/rbcs34_ 03.htm

França, L. H. de F. P., \& Carneiro, V. L. (2009). Programas de preparação para a aposentadoria: um estudo com trabalhadores mais velhos em Resende (RJ). Rev. Bras. Geriatr. Gerontol., 12(3). Recuperado em 3 de março, 2011, de: http://revista.unati.uerj.br/scielo.php?script=sci_arttext\&pid=S180 9-98232009000300010\&lng=pt\&nrm=iso

França, L. H. de F. P., \& Soares, D. H. P. (2009) Preparación para la jubilación como parte de la educación a lo largo de la vida. Psicol. cienc. prof., 29(4), 738-751. Recuperado em 16 de abril, 2011, de http://pepsic.bvsalud.org/scielo.php?script=sci_ arttext\&pid=S1414-98932009000400007\&lng=pt\&nrm=iso

França, L. H. de F. P., Vaughan, G. (2008). Ganhos e perdas: atitudes dos executivos brasileiros e neozelandeses frente à aposentadoria. Psicol. estud., 13(2), 207-216. Recuperado em 16 de abril, 2011, da SciELO (Scientific Electronic Library On line): www.scielo.br

Frankl, V. E. (1978/1989). Psicoterapia e Sentido da vida: Fundamentos da Logoterapia e análise existencial. São Paulo: Quadrante.

Freud, S. (1925/1997). A negativa. Rio de Janeiro: Imago.

Freud, S. (1930/1997). O mal-estar na civilização. Rio de Janeiro: Imago.

Giatti, L., \& Barreto, S. M. (2003). Saúde, trabalho e envelhecimento no Brasil. Cad. Saúde Pública, 19(3). Recuperado em 8 de abril, 2011, da SciELO (Scientific Electronic Library On line): www.scielo.br

González Rey, F. L. (2002). Pesquisa qualitativa em Psicologia. São Paulo: Pioneira Thomson Learning.

Laville, C., \& Dionne, J. (1999). A construção do saber. Porto Alegre: Artes Médicas e UFMG.

Mata, D. da, Oliveira, C. W. de A., Pin, C., \& Resende, G. (2007). Quais Características das Cidades Determinam a Atração de Migrantes Qualificados? Recuperado em 4 de julho, 2011, de http://ipea.gov.br/sites/000/2/publicacoes/tds/td_1305.pdf

Morin, E., Tonelli, M. J., \& Pliopas, A. L. V. (2007). O trabalho e seus sentidos. Psicol. Soc., 19. Recuperado em 8 de abril, 2011, da SciELO (Scientific Electronic Library On line): www.scielo.br

Muniz, J. A. (1997). PPA: Programa de Preparação para o Amanhã. Estudos de Psicologia (Natal), 2(1), 198-204. Recuperado em 9 de fevereiro, 2012, de 
http://www.scielo.br/scielo.php?script=sci_arttext\&pid=S1413294X1997000100012\&lng=en\&nrm=iso

Rodrigues, M., Ayabe, N. H., Lunardelli, M. C. F., \& Canêo, L. C. (2005). for a preparação para a aposentadoria: o papel do psicólogo frente a essa questão. Revista Brasileira de Orientação Profissional, 6(1), 53-62. Recuperado em 9 de fevereiro, 2012, de

http://pepsic.bvsalud.org/scielo.php?script=sci_arttext\&pid=S167 9-33902005000100006\&lng=pt\&nrm=iso

Shultz, K. S., Morton, K. R., \& Weckerle, J. R. (1998). The influence of push and pull factors on voluntary and involuntary early retirees' retirement decision and adjustment. Journal of Vocational Behavior, 53, 45-57.

Soares, W. (2002). Para além da concepção metafórica de redes sociais: fundamentos teóricos da circunscrição topológica da migração internacional. Anais do Encontro da Associação
Brasileira de Estudos Populacionais, 13 (pp. 1-27). Ouro Preto, MG.

Tolfo, S. R., \& Piccinini, V. (2007). Sentidos e significados do trabalho: explorando conceitos, variáveis e estudos empíricos brasileiros. Psicologia \& Sociedade, 19, 38-46. Recuperado em 9 de fevereiro, 2012, de http://www.scielo.br/scielo.php?script=sci_arttext\&pid=S0102$71822007000400007 \& \operatorname{lng}=$ pt\&nrm=iso

\section{Endereço para correspondência:} Jacqueline de Oliveira Moreira. Rua Congonhas, 161 São Pedro, CEP 30330-100, Belo Horizonte-MG. E-mail: jackdrawin@yahoo.com.br. 